\title{
Evolution of the Fetal Heart Rate Patterns in Cerebral Palsy Associated With Umbilical Cord Troubles: A Nationwide Study
}

Junichi Hasegawa ( $\square$ hasejun@marianna-u.ac.jp )

St. Marianna University School of Medicine

Masahiro Nakao

Mie University Graduate School of Medicine

Tomoaki Ikeda

Mie University Graduate School of Medicine

\section{Satoshi Toyokawa}

The University of Tokyo

\section{Emi Jojima}

The Prevention Recurrence Committee, Obstetric Compensation System for Cerebral Palsy

\section{Shoji Satoh}

Oita Prefectural Hospital

\section{Kiyotake Ichizuka}

Showa University Northern Yokohama Hospital

Nanako Tamiya

University of Tsukuba

\section{Akihito Nakai}

Nippon Medical School

\section{Keiya Fujimori}

Fukushima Medical University

\section{Tsugio Maeda}

Maeda Clinic, Incorporated Association Anzu-kai

\section{Satoru Takeda}

Juntendo University Faculty of Medicine

\section{Hideaki Suzuki}

The Prevention Recurrence Committee, Obstetric Compensation System for Cerebral Palsy

\section{Shigeru Ueda}

The Prevention Recurrence Committee, Obstetric Compensation System for Cerebral Palsy

\section{Mitsutoshi Iwashita}

Kugayama Hospital

\section{Tsuyomu Ikenoue}




\section{Research Article}

Keywords: Cerebral palsy, umbilical cord, velamentous cord insertion, true knot, hyper-coiled cord, cord entanglement, hypoxia, fetal heart rate

Posted Date: June 3rd, 2021

DOl: https://doi.org/10.21203/rs.3.rs-523758/v1

License: (c) (1) This work is licensed under a Creative Commons Attribution 4.0 International License. Read Full License 


\section{Abstract \\ Background}

The aim of the present study was to clarify the evolution of the fetal heart rate (FHR) patterns in infants with cerebral palsy (CP) according to each type of umbilical cord trouble.

\section{Methods}

A case-control study was attempted in the subjects born from 2009 to 2014 and those with a birth weight of $>2000 \mathrm{~g}$, gestational age of $>33$ weeks, and disability due to CP, CP associated with (126 cases) and without (594 controls) umbilical cord troubles were compared.

\section{Results}

Therty-two were umbilical cord prolapse and 94 were other umbilical cord troubles coexisting antenatally. Abnormal FHR patterns had already been identified on admission in $13 \%$ of cases with umbilical cord prolapse and $40 \%$ of cases with cord trouble coexisting antenatally. A persistent non-reassuring pattern was significantly frequent in cases with cord trouble coexisting antenatally $(p=0.012)$ and less frequent in cases with umbilical cord prolapse $(p=0.003)$. Reactive-PD was significantly identified in $69 \%$ of the cases with umbilical cord prolapse and $35 \%$ of the cases with cord trouble coexisting antenatally, especially in the first stage of labor $(p<0.001)$.

\section{Conclusion}

Persistent non-reassuring patterns on admission and reactive-PD pattern during the 1 st stage of labor were characterized in infants with $\mathrm{CP}$ related to umbilical cord troubles coexisting antenatally.

\section{Background}

One known cause of cerebral palsy (CP) involves hypoxia-ischemia and acidemia, although the etiology of many cases of CP remains unknown [1]. Since placental and umbilical cord abnormalities are likely to induce a hypoxic fetal condition, the association between CP and these abnormalities has been previously reported[2, 3]. In fact, our previous nationwide report [4] demonstrated that major obstetric factors associated with CP after 33 weeks' gestation were placental abnormalities (31\%) and umbilical cord abnormalities (15\%).

Although population-based studies have found intrapartum hypoxia-ischemia to be present in a smaller percentage of term children, with $\mathrm{CP}$ ranging from $8 \%$ to $28 \%$ in developed countries, and the rate of $\mathrm{CP}$ 
persisting for over the past 30 years[1], CP may be associated with acute umbilical cord compression as well as chronic, insufficient feto-placental perfusion during the antepartum period.

The pathology of umbilical cord abnormality during labor might be associated with having a cord vulnerable to external force during uterine contraction, resulting in acute hypoxia-ischemia (intrapartum hypoxia-ischemia). However, among types of umbilical cord abnormalities, we supposed that an insufficiency in the umbilical cord blood flow might vary from the antepartum period to delivery. Therefore, we hypothesized that the assessment of fetal heart rate evolution patterns provides clues to the timing and preventability of injury in babies with $\mathrm{CP}$ associated with umbilical cord troubles.

In the present study, we aimed to clarify the evolution of the fetal heart rate (FHR) patterns in patients with $\mathrm{CP}$ according to each type of umbilical cord trouble.

\section{Methods}

A case-control study was performed. The subjects included children with CP who were approved for compensation by a review of the Operating Organization of the Japan Obstetric Compensation System for Cerebral Palsy (JOCSC). Details of the JOCSC were described in our previous report [4]. The JOCSC was launched in January 2009 to provide prompt no-fault compensation for children who were diagnosed with $\mathrm{CP}$ caused by trauma during labor and delivery and for their respective families. The JOCSC covers more than $99 \%$ of delivery institutions throughout Japan. The JOCSC also provides information that could help in prevention, early resolution of disputes, and improvement in the quality of obstetric health care. The case review for compensation is performed by a review committee. After patients are authorized as eligible to receive compensation by this review committee, their causes of $\mathrm{CP}$ were individually analyzed by the Causal Analysis Committee, which comprised obstetricians, pediatricians, midwives, and lawyers. Once collected, these individual cases were analyzed by the Recurrence and Prevention Committee.

Patients eligible for inclusion in the present study were children born from January 2009 to July 2014 and those with a birth weight of ${ }^{3} 2000 \mathrm{~g}$, gestational age of ${ }^{3} 33$ weeks, and disability due to CP independent of congenital causes or factors during the neonatal period or later. Disability was certified to be of first- or second-degree severity according to the grade of disability definitions in the Act on Welfare of Physically Disabled Persons. Multiple pregnancies and FHR tracings that could not be evaluated (clear tracing missing from the medical record) were excluded from the present study. Considerable causations of $\mathrm{CP}$ associated with (Cases) and without (Controls) umbilical cord troubles in each case were retrieved from reports of the Operating Organization of the JOCSC. Cases with undeterminable causations of CP were included in controls.

The evolution of the FHR patterns was retrospectively analyzed by four authors (J.H., M.N., T.I., and E.J.) in patients with $\mathrm{CP}$ associated with umbilical cord abnormalities. The FHR patterns were determined after careful discussion. The National Institute of Child Health and Human Development guidelines $[5,6]$ were applied when interpreting the FHR patterns. We categorized the evolution of patients into the following 
five groups based on the evolution of the FHR patterns between admission and delivery, as modified by Phelan et al. [7].

When an abnormal FHR pattern was observed from the initial FHR examination on admission for delivery, the following two groups were defined: (i) The persistent non-reassuring group comprised fetuses with non-reassuring FHR, usually with a decreased baseline variability on admission, and this pattern persisted until delivery. (ii) The persistent bradycardia group comprised fetuses with bradycardia or persistent severe decelerations with loss of variability from the beginning of the FHR tracing on admission and no recovery until delivery.

In contrast, when the normal FHR pattern was observed on admission, the following three groups were defined: (iii) The Hon pattern group comprised fetuses with a normal FHR pattern on admission. Consequently, there were recurrent severe decelerations (especially variable deceleration) with or without an increased baseline heart rate and decreased baseline variability. Finally, terminal prolonged deceleration (PD) or bradycardia occurred before delivery. (iv) The reactive-PD group comprised fetuses with a normal FHR pattern on admission; however, acute severe PD or bradycardia occurred before delivery. (v) The persistent reassuring group comprised fetuses with a normal FHR range during the entire course. (Table 1, Additional file 1).

Umbilical cord troubles analyzed in the present study included umbilical cord prolapse, marginal/velamentous cord insertion, multiple cord entanglement, a true knot, umbilical cord constriction, hyper-coiled cord, hypo-coiled cord, and a single umbilical artery. Frequencies of FHR evolution patterns were compared between cases with CP associated with umbilical cord troubles (Cases) and with other causes (Controls).

\section{Definitions}

Findings of the umbilical cord troubles in the present study were used based on medical records macroscopically and/or microscopically investigated by obstetricians or midwives in each delivery institution. However, usually, these definitions are used in each institution with reference to the Glossary of Obstetrics and Gynecology published by the Japan Society of Obstetrics and Gynecology[8].

Velamentous and marginal cord insertion: Velamentous cord insertion is an abnormal cord insertion in which the umbilical vessels diverge as they traverse between the amnion and chorion before reaching the placenta. When umbilical cord insertion is located just at the edge of the placenta without running through the membranous vessels, it is defined as marginal cord insertion.

Multiple umbilical cord entanglement: Umbilical cord entanglement is defined when one or more loops of the umbilical cord are encircled around any part of the fetus. In the present study, cases with two or more cord entanglements were included.

Umbilical cord constriction/ narrow cord: Diagnosis of umbilical cord constriction is made when the umbilical cord has one or more narrow parts by macroscopic evaluation, including umbilical ring 
constriction, constriction in the free loop, and narrow umbilical cord without Wharton's jelly.

True knot: True knot of the umbilical cord is formed when the fetus passes through a loop of the umbilical cord while being active in the uterus.

Abnormal umbilical coiling: Umbilical coiling index is calculated by dividing the total number of coils by the length of the cord in centimeters. Hyper- and hypo-coiled cord after delivery are defined with umbilical coiling indices of $\geq 0.3$ coils $/ \mathrm{cm}(>90 \%$ percentile) and $<0.1 \mathrm{coils} / \mathrm{cm}(<10 \%$ percentile $)[8]$.

Single umbilical artery: Diagnosis of a single umbilical artery is made macro- or microscopically when one umbilical artery is absent or obstructed.

Umbilical cord prolapse: Umbilical cord prolapse was diagnosed clinically when the free loop of the umbilical cord is prolapsed into or outside the vagina.

\section{Statistical analysis}

A two-sided p-value of 0.05 was used to define statistical significance. All analyses were conducted using Stata version 13.0 (STATA Corporation, College Station, TX). Continuous variables were reported as mean \pm standard deviation and were compared using Student's t-test or Mann-Whitney U-test. Integer variables were reported as median and range and were compared using the Mann-Whitney U-test. Categorical variables were reported as frequencies and were compared using Fisher's exact test.

\section{Results}

A study flow diagram is demonstrated in Figure 1. Among 1017 cases of CP from the JOCSC database, after the exclusion of 44 multiple pregnancies, 131 were considered to be associated with umbilical cord troubles and 842 were considered to be caused by other reasons. After exclusion of cases with missing FHR data, 126 cases with CP associated with umbilical cord troubles and 594 controls with CP associated with other causes were finally analyzed FHR evolution patterns.

The characteristics of the patients with $\mathrm{CP}$ involving umbilical cord troubles and other causes are shown in Table 2. The emergency cesarean section rate was significantly higher in cases of CP involving umbilical cord troubles than in controls $(p<0.001)$. The Apgar scores in cases of CP involving umbilical cord troubles were significantly lower than those in controls $(p<0.001)$. The use of a cervical ripening balloon was associated with CP involving umbilical cord troubles $(p<0.001)$.

Incidence of abnormal fetal heart rate evolution patterns in cases with cord prolapse, umbilical cord troubles coexisting antenatally, and control are shown in Figure 2. Of the cases, 32 were umbilical cord prolapse, and 94 were other umbilical cord troubles coexisting antenatally. Abnormal FHR patterns have already been identified on admission (persistent non-reassuring and persistent bradycardia) in $13 \%$ of cases with umbilical cord prolapse, $40 \%$ of cases with cord trouble coexisting antenatally, and $37 \%$ of control. In particular, compared to control, the persistent non-reassuring pattern was more frequent in 
cases with cord trouble coexisting antenatally $(\mathrm{p}=0.012)$ and less frequent in cases with umbilical cord prolapse $(p=0.003)$. Cases in which reassuring FHR pattern was observed on admission, but abnormal FHR patterns during labor, were more frequently observed in cases with cord troubles than in control. In particular, reactive-PD was significantly identified in $69 \%$ of cases with umbilical cord prolapse and $35 \%$ of cases with cord trouble coexisting antenatally, compared to $17 \%$ of control $(p<0.001)$. Reassuring FHR patterns continued until delivery were significantly less in umbilical cord troubles than in control.

Timing and type of evolution patterns of abnormal FHR stratified by umbilical cord troubles are demonstrated in Table 3. Abnormal FHR on admission was identified in various types of umbilical cord troubles, especially hyper-coiled cord (65\%) and velamentous cord insertion (50\%). On the other hand, abnormal FHR patterns in labor were likely to occur during the first stage in all types of umbilical cord troubles, but abnormal FHR pattern during the second stage of labor was identified in $18 \%$ of multiple cord entanglement. During the first stage of labor, reactive-PD was likely to be identified in umbilical cord prolapse, cord constriction, hypo-coiled cord, and single umbilical artery.

\section{Discussion}

While FHR evolution pattern in cases with umbilical cord prolapse was characterized as reactive-PD, FHR in cases with umbilical cord troubles coexisting antenatally were likely to be both persistent nonreassuring pattern on admission and reactive-PD during the first stage of labor, compared to cases resulting in $\mathrm{CP}$ not associated with umbilical cord troubles.

Concerning the timing of the hypoxic-ischemic injury, when the demonstration of an initially normal tracing followed by patterns of hypoxia/ischemia, such as reactive PD, and Hon patterns, it can be considered that $\mathrm{CP}$ was due to intrapartum hypoxic-ischemic injury in this analysis of the evolution of the FHR patterns during labor. Furthermore, in our interpretation of each evolution of the FHR pattern, reactive-PD is considered as acute events causing hypoxic-ischemic damage during labor, while Hon pattern is considered as relatively sub-acute stress, affecting fetal brain causing hypoxic-ischemic encephalopathy (Figure 3).

It is reasonable that reactive-PD pattern was identified in various types of umbilical cord troubles, especially during the first stage of labor because an abnormal FHR pattern and insufficient umbilical cord blood flow often originate from the vulnerability of the umbilical cord congenitally coexisted with developing placenta. For example, in fetuses with velamentous cord insertion, an abnormal FHR and perinatal complications are caused by a lack of Wharton's jelly, which results in compression of weak membranous vessels [9-12]. The hyper-coiled cord could be more prone to cord torsion than to compression or stretching, which adversely affects blood flow during uterine contractions $[13,14]$. It is reported that variable decelerations were more frequently present, especially during the first stage of labor in cases with a morphologically abnormal umbilical cord, such as velamentous cord insertion and hypercoiled cord than in cases without abnormal umbilical cord [10,11]. 
FHR monitoring of fetuses with umbilical cord troubles coexisting antenatally also often tended to result in Hon pattern. We think the appearance of Hon pattern might be caused by compressive and/or noncompressive failure of umbilical blood flow. Partial or progressive compression of the umbilical cord might build Hon pattern. On the other hand, when the previously normal tracing evolves slowly to severe abnormality through late or variable decelerations, this also suggests a mechanism of hypoxemic/acidemic basis for the injury which may yet be related to a non-compressive failure of umbilical blood flow. Structural umbilical cord abnormalities developed in the earlier gestation are likely to coexist with placental abnormalities $[12,15]$. We suppose, in such cases, insufficient fetoplacental perfusion during the progression of labor can induce abnormal FHR patterns, resulted in Hon pattern. In fact, Hon pattern was identified in all cases with velamentous insertion which is often concomitant with abnormal placental growth.

In the evolution pattern of abnormal FHR on admission, persistent-bradycardia was identified in cases with some umbilical cord troubles coexisting antenatally. We suppose these cases had already suffered acute or sub-acute compressive failure of umbilical blood flow before admission resulting in bradycardia and traced FHR since admission.

Contrary to the acute and sub-acute adverse event, persistent non-reassuring pattern indicates that causal events occurred over a relatively wide range, such as days or weeks before labor onset. In the present result, persistent non-reassuring patterns, such as absent or minimal baseline variability and bradycardia from the beginning of the FHR tracing on admission even before the onset of labor was present in various types of umbilical cord troubles coexisting antenatally. Without some overt incriminating cord problem to explain a pre-existing abnormality of the fetal tracing, one cannot be certain of the mechanism of preceding injury other than the notion that the timing was likely prepartum. A previous study showed that umbilical cord abnormalities, which can obstruct umbilical cord blood flow, were significantly increased in neonates with placental fetal thrombo-coagulopathy (FTV) who later developed CP [3]. A potentially obstructive pathological umbilical cord, including decreased Wharton's jelly, a narrow cord and a hypercoiled cord, is also more frequent in neonates with FTV (30\% vs. $9 \%$ in those without FTV) [3]. Our results can support this previous study.

Concerning the preventability, those with pre-existing abnormal FHR patterns seem unlikely to be preventable (persistent non-reassuring and bradycardia), while those with initially normal tracings and obvious deterioration would seem to be at least potentially preventable, especially Hon pattern. On the other hand, the prevention of $\mathrm{CP}$ in cases had severe prolonged deceleration or continuous bradycardia might be difficult. In the previous study in Japan, which demonstrated the prognosis of infants with umbilical cord prolapse, the interval from the diagnosis of prolapse to delivery was found to be significantly longer in infants with a poor outcome than in infants with intact survival (median, 30 vs. 24 min.) [16]. Unless obstetric facilities throughout Japan can provide the immediate cesarean section within 15 min, we will not be able to reduce such CP cases. Unfortunately, half of the deliveries in Japan are managed in private clinics, which is not available emergency cesarean section. 
Previous studies suggested that suboptimal intrapartum care could offer an obvious preventive opportunity of labor asphyxia, in particular cases with normal admission FHR patterns $[17,18]$. The combination of FHR monitoring with maternal, obstetrical, and fetal risk factors performed much better as a screening test than FHR monitoring alone [19]. Furthermore, ultrasound screening of umbilical cord abnormalities, triage of pregnant women according to risks of emergency cesarean section, and appropriate management of FHR and delivery are recommended [20, 21]. At least, for early detection of abnormal FHR related to umbilical cord abnormality, pregnant women having umbilical cord abnormality diagnosed by the antenatal ultrasound should better be placed under the continuous observation of FHR with preparing emergency cesarean section when contractions begin.

This large nationwide study has shown various FHR evolution patterns in neonates with CP born after 33 weeks' gestation in association with umbilical cord troubles. As a limitation of the present study, because this was performed based on a review of the medical records, evaluations of umbilical cord abnormalities were attempted by obstetricians or midwives in each delivery institution, though definitions are standardized by the Glossary of Obstetrics and Gynecology published by Japan Society of Obstetrics and Gynecology. Furthermore, since we only analyzed cases of CP in neonates with a birth weight of ${ }^{3} 2000 \mathrm{~g}$ and gestational age of ${ }^{3} 33$ weeks as study subjects and did not analyze the associations among $\mathrm{CP}$, umbilical cord abnormalities, and fetal growth restriction. A persistently reassuring pattern also might exclude the events of labor as etiologic in the injury. This sequence suggests that the etiology of the problem is either a traumatic delivery, very early injury with apparent recovery of the tracing, or unrecognized. Further additional analyses associated with these obstetric factors are needed.

\section{Conclusion}

In infants with CP related to various umbilical cord troubles coexisting antenatally, persistent nonreassuring patterns on admission and reactive-PD pattern during the 1st stage of labor were more frequently identified, compared to infants with $\mathrm{CP}$ without umbilical cord troubles.

\section{List Of Abbreviations}

$\mathrm{CP}$; cerebral palsy, FHR; fetal heart rate, JOCSC; the Operating Organization of the Japan Obstetric Compensation System for Cerebral Palsy, FTV; fetal thrombo-coagulopathy, P-Brady; persistent brady, PNR; persistent non-reassuring, R-PD; reactive-prolonged deceleration

\section{Declarations}

\section{Ethics approval and consent to participate}

All procedures performed in studies involving human participants were in accordance with the ethical standards of the institutional and/or national research committee and with the 1964 Helsinki declaration and its later amendments or comparable ethical standards. The study protocol was approved by the 
Institutional Review Boards (IRBs) of the JOCSC (No.26-01, Aug. 5th, 2014). Written informed consent was not obtained from patients. However, patients were provided the announcement of the implementation of a "case-control study for cerebral palsy and prevention of its recurrence." (Additional file 2) Although the analysis was retrospective, data for the anonymized JOCSC database were collected in a normal clinical setting and the confidentiality of the patients involved was protected. All patients' records/information was anonymized and de-identified before analysis.

\section{Consent for publication}

Not applicable

\section{Availability of data and materials}

The datasets generated and/or analysed during the current study are not publicly available. The data in the JOCSC were obtained with cooperation from the birthing facilities and families. It is, therefore, necessary for this organization to handle personal information with great care, and thus our policy is not to provide outside access to these data. An article in the Standard Conditions of the Japan Obstetric Compensation System stipulates that access to the personal information of children who develop cerebral palsy and their families, as well as of the birthing facilities, is strictly limited to the staff of JCQHC.

\section{Competing interests}

he authors declare that they have no competing interests.

\section{Funding}

None

\section{Authors' contributions}

$\mathrm{JH}, \mathrm{NM}, \mathrm{TI}$, and $\mathrm{TI}$ conceived the study. $\mathrm{JH}$ wrote the initial protocol, analyzed the data, and wrote the first draft of the manuscript. All authors collected data and analyzed cases of $\mathrm{CP}$. JH, MN, TI, and EJ coordinated the study, and $\mathrm{JH}, \mathrm{MN}, \mathrm{TI}$, and EJ produced the database. ST and NT performed statistical analyses. All authors contributed to writing the manuscript. TI, SS, KI, ST, AN, KF, TM, ST, HS, SU and TI are the guarantors for the study. All authors had full access to all of the data in the study and take responsibility for the integrity of the data and the accuracy of the data analysis. The lead author affirms that this manuscript is an honest, accurate, and transparent account of the study being reported; that no important aspects of the study have been omitted; and that any discrepancies from the study as planned have been explained.

\section{References}


1. Graham EM, Ruis KA, Hartman AL, Northington FJ, Fox HE: A systematic review of the role of intrapartum hypoxia-ischemia in the causation of neonatal encephalopathy. American journal of obstetrics and gynecology 2008, 199(6):587-595.

2. Nakamura M, Umehara N, Ishii K, Sasahara J, Kiyoshi K, Ozawa K, Tanaka K, Tanemoto T, Ichizuka K, Hasegawa $\mathrm{J}$ et al: A poor long-term neurological prognosis is associated with abnormal cord insertion in severe growth-restricted fetuses. Journal of perinatal medicine 2018, 46(9):1040-1047.

3. Redline RW: Clinical and pathological umbilical cord abnormalities in fetal thrombotic vasculopathy. Human pathology 2004, 35(12):1494-1498.

4. Hasegawa J, Toyokawa S, Ikenoue T, Asano Y, Satoh S, Ikeda T, Ichizuka K, Tamiya N, Nakai A, Fujimori K et al: Relevant Obstetric Factors for Cerebral Palsy: From the Nationwide Obstetric Compensation System in Japan. PloS one 2016, 11(1):e0148122.

5. Macones GA, Hankins GD, Spong CY, Hauth J, Moore T: The 2008 National Institute of Child Health and Human Development workshop report on electronic fetal monitoring: update on definitions, interpretation, and research guidelines. Obstetrics and gynecology 2008, 112(3):661-666.

6. Electronic fetal heart rate monitoring: research guidelines for interpretation. National Institute of Child Health and Human Development Research Planning Workshop. American journal of obstetrics and gynecology 1997, 177(6):1385-1390.

7. Phelan JP, Ahn MO: Fetal Heart Rate Observations in 300 Term Brain-damaged Infants. Journal of maternal-fetal investigation : the official journal of French Society of Ultrasound in Medicine and Biology [et al] 1998, 8(1):1-5.

8. Strong TH, Jr., Jarles DL, Vega JS, Feldman DB: The umbilical coiling index. American journal of obstetrics and gynecology 1994, 170(1 Pt 1):29-32.

9. Hasegawa J, Matsuoka R, Ichizuka K, Sekizawa A, Okai T: Ultrasound diagnosis and management of umbilical cord abnormalities. Taiwanese journal of obstetrics \& gynecology 2009, 48(1):23-27.

10. Hasegawa J, Matsuoka R, Ichizuka K, Nakamura M, Sekizawa A, Okai T: Do fetal heart rate deceleration patterns during labor differ between various umbilical cord abnormalities? Journal of perinatal medicine 2009, 37(3):276-280.

11. Hasegawa J, Matsuoka R, Ichizuka K, Kotani M, Nakamura M, Mikoshiba T, Sekizawa A, Okai T: Atypical variable deceleration in the first stage of labor is a characteristic fetal heart-rate pattern for velamentous cord insertion and hypercoiled cord. The journal of obstetrics and gynaecology research 2009, 35(1):35-39.

12. Hasegawa J, Matsuoka R, Ichizuka K, Sekizawa A, Farina A, Okai T: Velamentous cord insertion into the lower third of the uterus is associated with intrapartum fetal heart rate abnormalities. Ultrasound Obstet Gynecol 2006, 27(4):425-429.

13. Predanic M, Perni SC, Chervenak FA: Antenatal umbilical coiling index and Doppler flow characteristics. Ultrasound Obstet Gynecol 2006, 28(5):699-703.

14. Georgiou HM, Rice GE, Walker SP, Wein P, Gude NM, Permezel M: The effect of vascular coiling on venous perfusion during experimental umbilical cord encirclement. American journal of obstetrics 
and gynecology 2001, 184(4):673-678.

15. Hasegawa J, Matsuoka R, Ichizuka K, Otsuki K, Sekizawa A, Farina A, Okai T: Cord insertion into the lower third of the uterus in the first trimester is associated with placental and umbilical cord abnormalities. Ultrasound Obstet Gynecol 2006, 28(2):183-186.

16. Hasegawa J, Sekizawa A, Ikeda T, Koresawa M, Ishiwata I, Kawabata M, Kinoshita K, Japan Association of $\mathrm{O}$, Gynecologists: Clinical risk factors for poor neonatal outcomes in umbilical cord prolapse. J Matern Fetal Neonatal Med 2016, 29(10):1652-1656.

17. Jonsson M, Agren J, Norden-Lindeberg S, Ohlin A, Hanson U: Suboptimal care and metabolic acidemia is associated with neonatal encephalopathy but not with neonatal seizures alone: a population-based clinical audit. Acta obstetricia et gynecologica Scandinavica 2014, 93(5):477-482.

18. Jonsson M, Agren J, Norden-Lindeberg S, Ohlin A, Hanson U: Neonatal encephalopathy and the association to asphyxia in labor. American journal of obstetrics and gynecology 2014, 211(6):667 e661-668.

19. Eden RD, Evans MI, Evans SM, Schifrin BS: The "Fetal Reserve Index": Re-Engineering the Interpretation and Responses to Fetal Heart Rate Patterns. Fetal Diagn Ther 2018, 43(2):90-104.

20. Takita H, Hasegawa J, Arakaki T, Nakamura M, Tokunaka M, Oba T, Sekizawa A: Antenatal ultrasound screening using check list before delivery for predicting a non-reassuring fetal status during labor. J Matern Fetal Neonatal Med 2018, 31(1):1-6.

21. Hasegawa J: Ultrasound screening of umbilical cord abnormalities and delivery management. Placenta 2018, 62:66-78.

\section{Tables}

Due to technical limitations, table 1,3 is only available as a download in the Supplemental Files section.

Table 2: Major obvious obstetric factors considered as association with cerebral palsy 
Variables

Umbilical cord troubles

(Cases: $\mathrm{n}=131$ )
Other causes

$\mathrm{p}$ value

(Controls: $\mathrm{n}=\mathbf{8 4 2}$ )

Maternal characteristics

\begin{tabular}{llllll} 
Age & $31.6 \pm$ & 5.4 & $31.2 \pm$ & 5.1 & 0.544 \\
\hline Height $(\mathrm{cm})$ & $157.4 \pm$ & 5.8 & $157.6 \pm$ & 5.6 & 0.761 \\
\hline Weight at beginning of pregnancy $(\mathrm{kg})$ & $52.5 \pm$ & 7.8 & $53.6 \pm$ & 9.6 & 0.186 \\
\hline $\mathrm{BMI}\left(\mathrm{kg} / \mathrm{m}^{2}\right)$ & $21.2 \pm$ & 2.9 & $21.6 \pm$ & 3.8 & 0.210 \\
\hline Weight at delivery $(\mathrm{kg})$ & $62.6 \pm$ & 8.2 & $63.3 \pm$ & 9.3 & 0.392 \\
Weight gain $(\mathrm{kg})$ & $10.2 \pm$ & 3.9 & $9.9 \pm$ & 4.0 & 0.380 \\
\hline Parity (median, range) & 0 & $(0-4)$ & 0 & $(0-5)$ & 0.621 \\
\hline In vitro fertilization & $4.6 \%$ & $(6)$ & $3.4 \%$ & $(29)$ & 0.516
\end{tabular}

Delivery characteristics

Premature rupture of the membranes

$23.7 \%$

(31)

$23.2 \%$

(195)

0.899

Use of a cervical ripening balloon

$16.8 \%$

(22)

$5.9 \%$

(50) $\quad<0.001$

Augmentation

$35.1 \%$

(46)

$29.3 \%$

(247)

0.180

Uterine fundal pressure

$20.6 \%$

(27)

$17.9 \%$

(151)

0.461

Mode

Normal spontaneous

$18.3 \%$

(24)

$37.6 \%$

(317) $\quad<0.001$

Instrumental

$16.8 \%$

(22)

$14.3 \%$

(120)

0.443

Elective CS

$0.0 \%$

(0)

$4.2 \%$

(35)

0.017

Emergency CS

$61.1 \%$

(80)

$43.9 \%$

(370) $\quad<0.001$

Delivery at

$\begin{array}{llllll}\text { Hospital } & 56.4 \% & (74) & 62.6 \% & (527) & 0.181 \\ \text { Clinic } & 38.9 \% & (51) & 36.6 \% & (308) & 0.604 \\ \text { Midwifery home } & 0.8 \% & (1) & 0.8 \% & (7) & 1.000 \\ \text { Maternal transport after onset of labor } & 6.9 \% & (9) & 10.0 \% & (84) & 0.261 \\ \text { Neonatal outcomes } & & & & & \\ \text { Gestational weeks } & 38.6 \pm & 1.9 & 38.3 \pm & 3.1 & 0.790 \\ \text { Birth weight (g) } & 2861 \pm & 449 & 2858 \pm & 448 & 0.950\end{array}$




\begin{tabular}{|llllll|}
\hline Birth weight (SD) & $-0.31 \pm$ & 0.99 & $-0.17 \pm$ & 1.03 & 0.144 \\
\hline Male & $54.8 \%$ & $(69)$ & $56.3 \%$ & $(474)$ & 0.437 \\
\hline Apgar score at 1 min (median, range) & $\mathbf{1}$ & $\mathbf{( 0 - 1 0 )}$ & $\mathbf{3}$ & $\mathbf{( 0 - 1 0 )}$ & $<0.001$ \\
\hline$<7$ & $\mathbf{9 3 . 1 \%}$ & $\mathbf{( 1 2 2 )}$ & $\mathbf{6 7 . 3 \%}$ & $\mathbf{( 5 6 7 )}$ & $<0.001$ \\
\hline$<4$ & $\mathbf{7 6 . 3 \%}$ & $\mathbf{( 1 0 0 )}$ & $\mathbf{5 3 . 4 \%}$ & $\mathbf{( 4 5 0 )}$ & $<0.001$ \\
\hline Apgar score at 5 min (median, range) & $\mathbf{3}$ & $\mathbf{( 0 - 1 0 )}$ & $\mathbf{5}$ & $\mathbf{( 0 - 1 0 )}$ & $<0.001$ \\
\hline$<7$ & $\mathbf{7 9 . 4 \%}$ & $\mathbf{1 0 4}$ & $\mathbf{5 6 . 1} \%$ & $\mathbf{4 7 2}$ & $<0.001$ \\
\hline$<4$ & $\mathbf{4 8 . 9 \%}$ & $\mathbf{6 4}$ & $\mathbf{3 1 . 6 \%}$ & $\mathbf{2 6 6}$ & $<0.001$ \\
\hline Umbilical artery pH (mean, SD) & $7.034 \pm$ & 0.228 & $7.053 \pm$ & 0.280 & 0.534 \\
\hline$<7.2$ & $42.7 \%$ & $(56)$ & $38.0 \%$ & $(320)$ & 0.300 \\
\hline$<7.0$ & $26.7 \%$ & $(35)$ & $27.1 \%$ & $(228)$ & 0.931 \\
\hline
\end{tabular}

Data indicate mean \pm standard deviation, median (range), or frequency (n).

BMI, body mass index; CS, cesarean section; SD, standard deviation

\section{Figures}




\section{Cerebral palsy:}

Children who were approved for compensation by the Japan Obstetric Compensation System for cerebral palsy from $2009-2014$ without congenital anomalies and neonatal factors

Birth weight $\geq 2000 \mathrm{~g}$

Gestational weeks $\geq 33$

$n=1017$

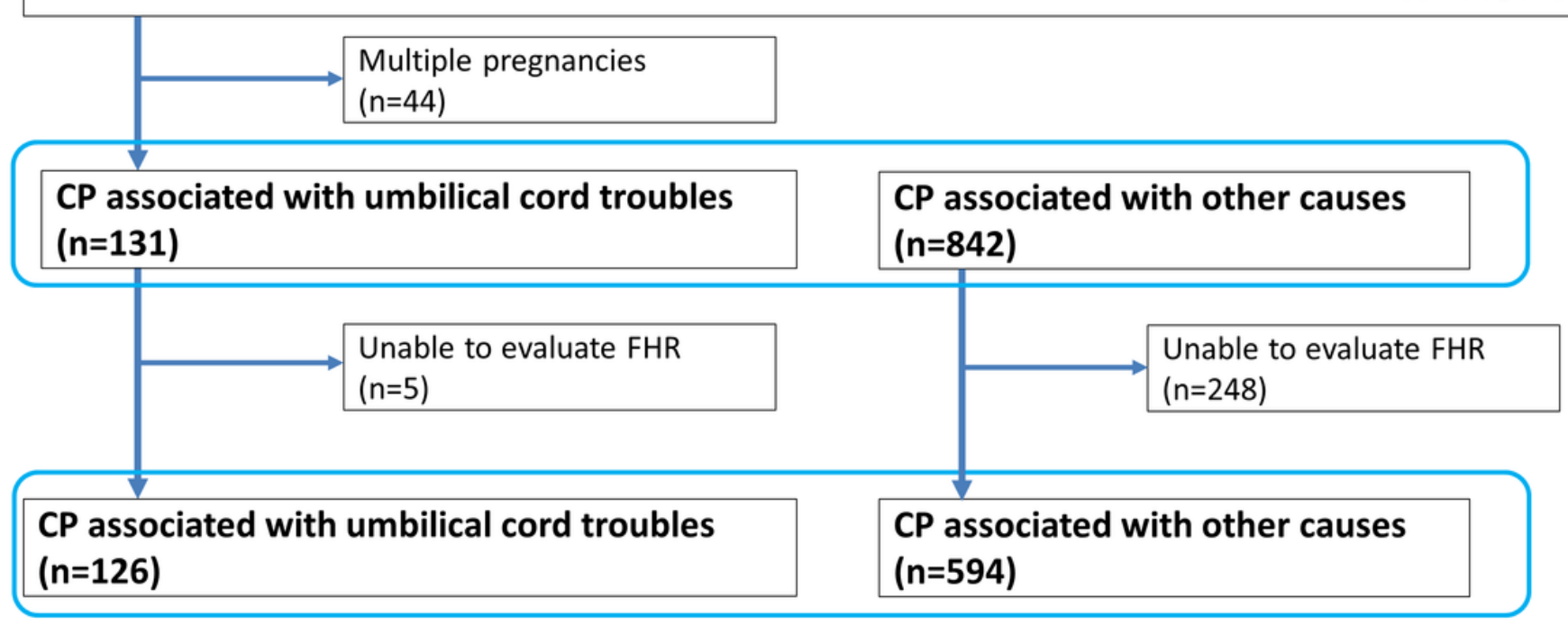

\section{Final analysis Evaluation of FHR monitoring}

\section{Figure 1}

Study flow diagram 


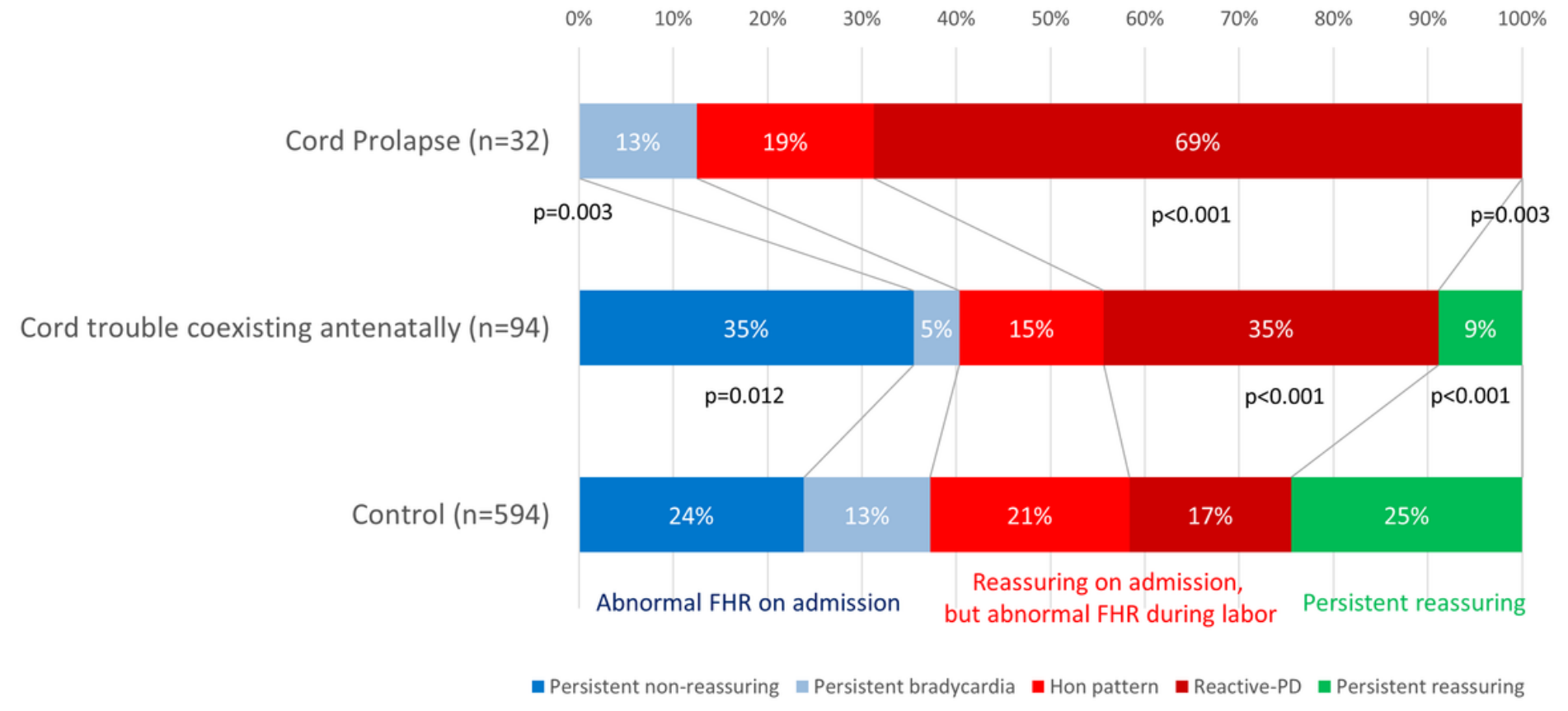

*: $p<0.01$ compared to Control

\section{Figure 2}

Incidence of abnormal fetal heart rate evolution patterns in cases with cord prolapse, umbilical cord troubles coexisting antenatally and control 
Antepartum Intrapartum Neonatal

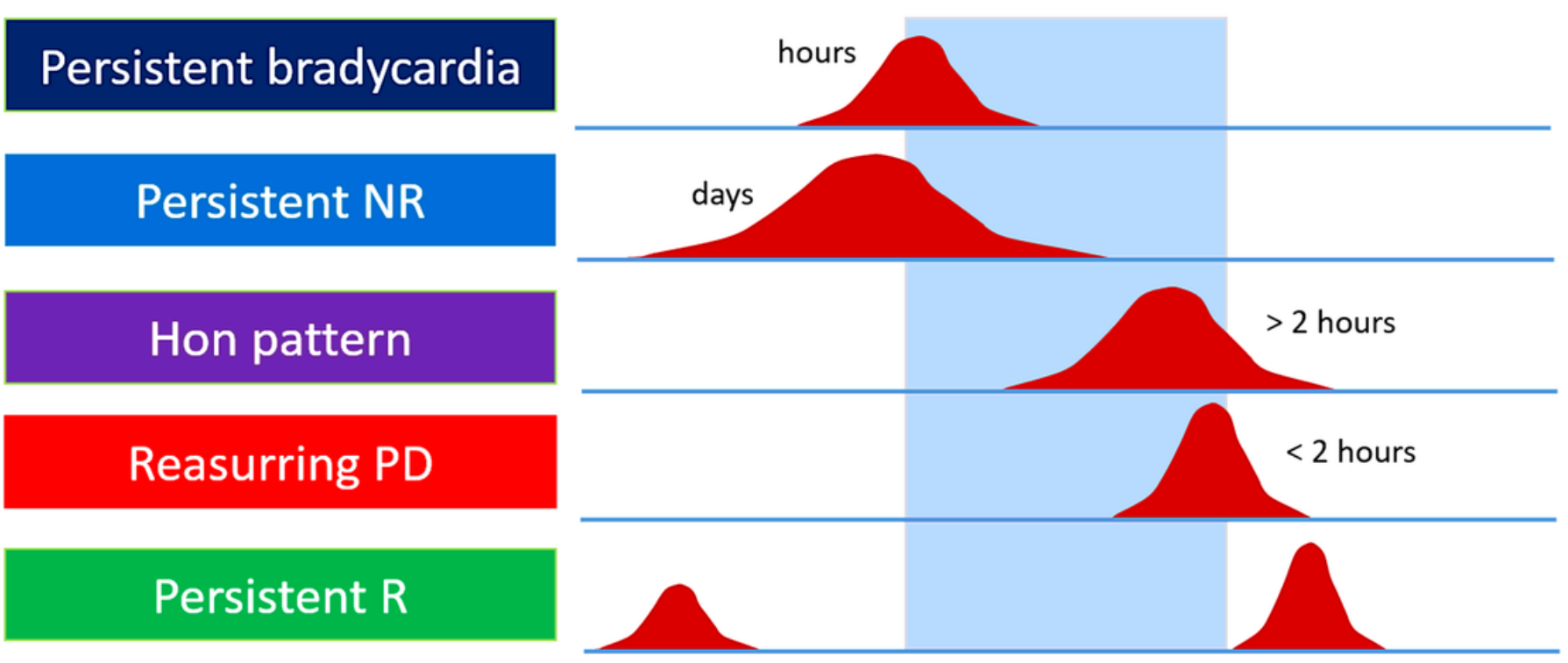

Figure 3

Categorization in contemplating the timing of causal event of cerebral palsy

\section{Supplementary Files}

This is a list of supplementary files associated with this preprint. Click to download.

- Additionalfile1.pptx

- Table3.jpg

- Additionalfile2.docx

- Table1.jpg 